\title{
Tests on Seismic Behavior of Pre-cast Shear Walls with Vertical Reinforcements Spliced by Two Different Grout Ways
}

\author{
Lv Yajun ${ }^{*}{ }^{1}$ and Guan Naiyan ${ }^{2}$ \\ ${ }^{1}$ Architecture College of North China University of Water Resources and Electric Power, Zhengzhou, Henan, 450000, \\ P.R. China \\ ${ }^{2}$ Architecture College of Tianjin University, Tianjin,370002, P.R. China
}

\begin{abstract}
To evaluate the seismic performance of pre-cast concrete shear wall with vertical reinforcements spliced by two different grout ways, quasi-static tests of two concrete shear walls holed by prefabricated corrugated pipe and one concrete shear wall holed by drawing out the pipe were tested. The test results showed that the wall holed by prefabricated corrugated pipe was basically the same as the wall holed by drawing out the pipe in failure modes. The hysteretic curves of the specimens are full, the trend of the skeleton curve is basically the same and the capacity of the energy dissipation is close. The displacement ductility factors are more than 4 . For the two walls holed by prefabricated corrugated pipe, when the lap length is reduced, the seismic performance decline as well, but the wall still meets the current seismic code requirements.
\end{abstract}

Keywords: Pre-cast shear wall, restraint anchor, the way of hole, seismic behavior, quasi-static test.

\section{INTRODUCTION}

Pre-cast concrete shear wall structure is suitable for residence industrialization, which has the advantages of convenience in construction, easy-to-control quality, reducing energy and water usage, producing less construction trash and lower cost. In addition, Chinese government is promoting green building technology and application, and the construction process of pre-cast concrete shear wall structure has the characteristic of green construction, therefore it is the development tendency of the future construction (Zhu 2003, Guo 2011) [1, 2]. Many studies have investigated the performance of pre-cast concrete shear wall. Qian et al. (2011a, 2011b) [3, 4] study seismic behavior of pre-cast reinforced concrete (RC) shear walls with vertical reinforcements spliced by grout sleeves, test results showed that the integrity behavior of the rough interface of the side face of the pre-cast wall is better than that of the shear keys. Jiang et al. (2011) [5] studied the connection method between reinforced bars of the pre-cast concrete structure, and the basic anchoring length of plug-in filling hole for lap-joint of steel bar was given. Zhu et al. (2012) [1] studied the seismic performance of joints of new pre-cast concrete shear wall structures. Some foreign researchers had done a lot of experiments and researches on the seismic performance of pre-cast concrete wall (Pekau 1988, Mochizuki 1981, Harry 1982, Oliva 1982, Nazza 2005) [6-10].

*Address correspondence to this author at the Architecture College of North China University of Water Resources and Electric Power, Zhengzhou, Henan, 450000, P.R. China; Tel: 18637112946;

E-mail: darkdanking@126.com
At present, grout sleeve splicing and restraint grout splicing are the main connections for vertical reinforcements in the construction process of pre-cast concrete wall. In order to reduce the overlap length of grout splicing, Jiang et al. (2011, Liu 1981) [11, 12] developed the restraint grout splicing, as shown in Fig. (1). The technology reduced the overlap length by increasing stirrup bars within the range of lapped segments, and the hole was formed by drawing out the screwed steel pipes, which is complicated and difficult to control. In order to simplify the process, the wall holed by prefabricated corrugated pipe was used. The main objective of this research is to evaluate the feasibility of restraint grout splicing.
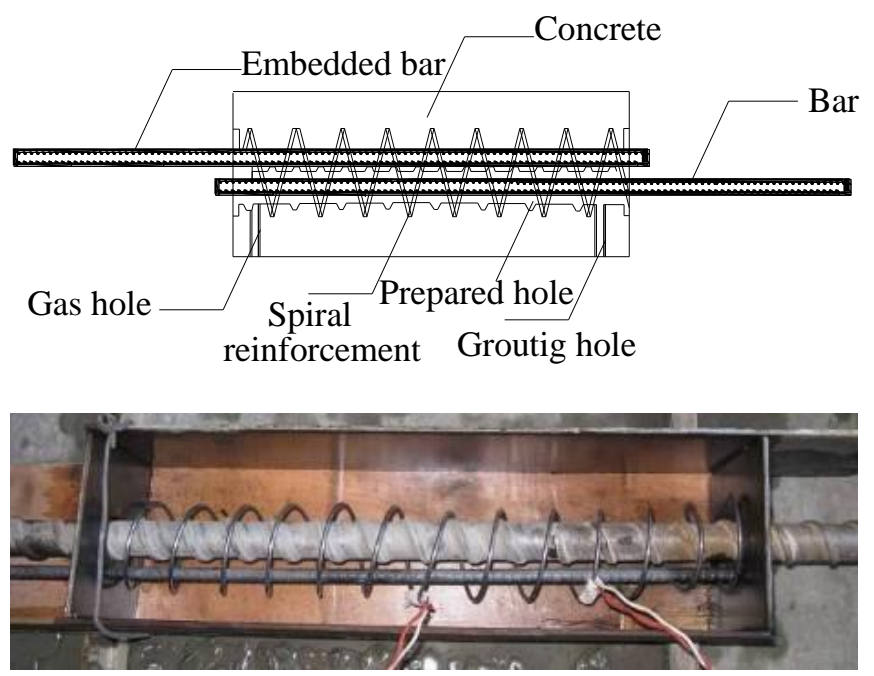

Fig. (1). The overlap method. 


\section{EXPERIMENTAL PROGRAM}

\subsection{Specimen Preparation}

Three full-scale pre-cast concrete walls were tested to evaluate their seismic performance, which were designed with the specification of Technical specification for concrete structures of tall building and Specification of testing methods for earthquake resistant building JGJ101-1996. Structure of restraint grout splicing is shown in Fig. (2a), where 1 is the longitudinal bar in the shear walls, 2 is spiral stirrups, 3 is the horizontal bar in the shear walls, 4 is corrugated pipe, 5 is mortar layer, 6 is the bar embedded in the strip foundation. The details of the specimens are shown in Table $\mathbf{1}$ and Fig. (2b). The pre-cast concrete walls were $2000 \mathrm{~mm}$ in width, $3000 \mathrm{~mm}$ in height and $200 \mathrm{~mm}$ in thickness. The concrete compressive strength of the wall after 28 days was $37 \mathrm{MPa}$, and the compressive strength of grouting material after 28 days was $37 \mathrm{MPa}$. The yield strength (fy), tensile strength (fu) and elongation of different steel is listed in Table $\mathbf{2}$.

In the preparation process of the specimen, it was intended that the wall panel reinforcing cage could be manufactured as two independent units (an upper pre-cast wall and lower strip foundation), required only to be brought together at the commencement of casting. The steel corrugated pipes were reserved in the upper wall, and grouting material was filled in the hole when the installation of upper and lower portion was complete. The mortar layer and filling hole for steel bar should be filled with grouting material at the same time to make sure the integrality.

\subsection{Experimental Infrastructure}

Fig. (3) depicts the loading frame used for conducting the experiments. Lateral loading was applied to each unit through the use of a $5000 \mathrm{kN}$ servo-controlled hydraulic actuator. This actuator was bolted to the reaction wall. To provide axial stress similitude between specimen and prototype, a 5000kN hydraulic jack was used. Two steel supports were used to provide lateral stability to the wall. Four displacement sensors with a range of $100 \mathrm{~mm}$ were placed on one side of the wall to monitor the lateral displacements.

\subsection{Loading Program}

To check the alignment, the axial load was applied with an interval of $500 \mathrm{kN}$, and the strain and displacement sensors were monitored regularly. After the final positioning,

Table 1. Details of the specimen.

\begin{tabular}{|c|c|c|c|}
\hline Specimen & Axial compression ratio & overlapped length & Method to form hole \\
\hline \hline BW9 & 0.2 & $0.91 \mathrm{ae}$ & Prefabricated corrugated pipe \\
\hline GJ9 & 0.2 & $0.91 \mathrm{ae}$ & Drawing out the pipe \\
\hline BW7 & 0.2 & $0.71 \mathrm{lae}$ & Prefabricated corrugated pipe \\
\hline
\end{tabular}

Table 2. Material properties of steel.

\begin{tabular}{|c|c|c|c|c|}
\hline Reinforcement & Diameter $(\mathbf{m m})$ & $\boldsymbol{f}_{\mathbf{y}}(\mathbf{M P a})$ & $\boldsymbol{f}_{\mathbf{u}}$ MPa & Elongation \% \\
\hline \hline HRB400 & 6 & 472 & 635 & 29 \\
\hline HRB400 & 8 & 430 & 685 & 27 \\
\hline HRB400 & 10 & 545 & 655 & 27 \\
\hline HRB400 & 12 & 495 & 655 & 27 \\
\hline
\end{tabular}
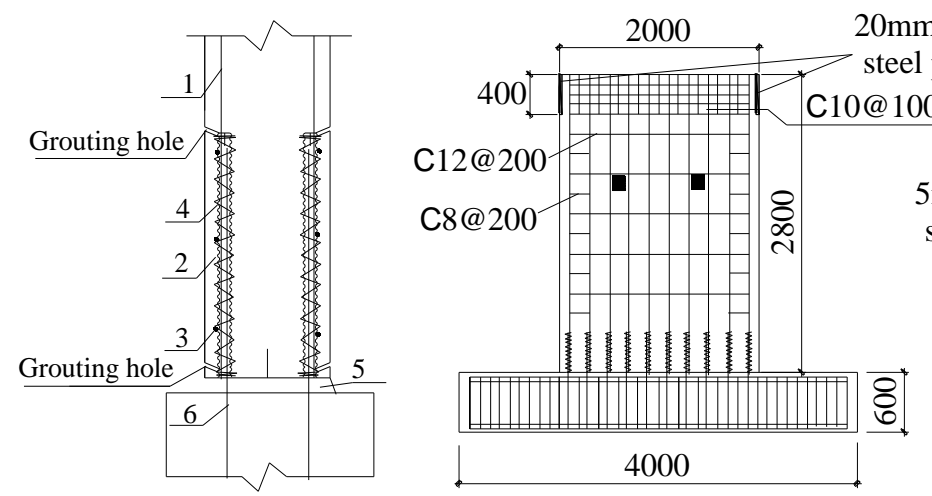

$20 \mathrm{~mm}$ embedded

(a) Structure of restraint grout splicing

Fig. (2). The structure and details of specimen.

(b) Details of specimen 
the alignment was checked up to the maximum predetermined axial load. Then, the lateral load actuator was connected to the specimen after the application of full axial load. A reverse cyclic lateral load was applied in terms of load and displacement control as shown in Fig. (4). Before the specimen yielded, one cycle was applied at each of the elastic lateral load. At each level of ductility displacement $(\Delta y)$, three full cycles of reverse lateral load were applied. Test was conducted until either the specimen failed due to large deformation or the lateral load resistance of the specimen had deteriorated to $85 \%$ of the lateral bearing capacity.
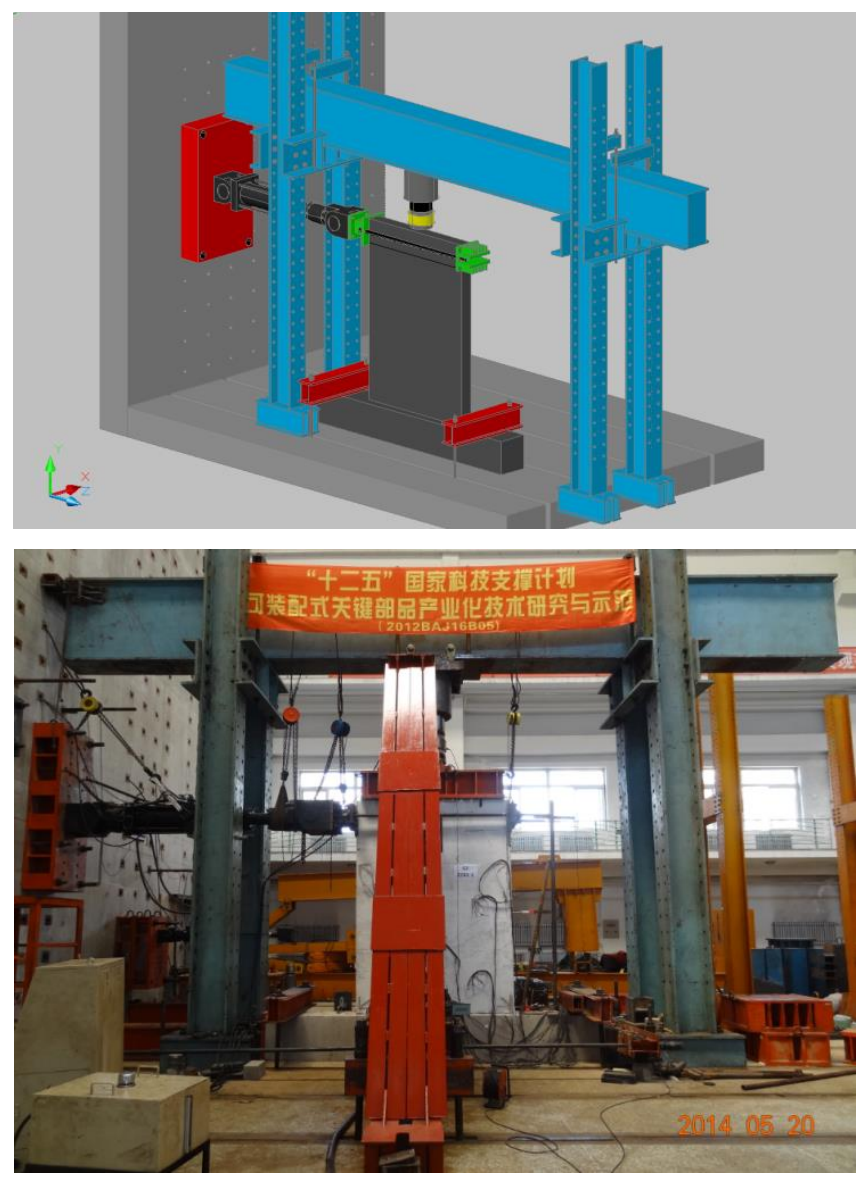

Fig. (3). Schematic representation of loading frame.

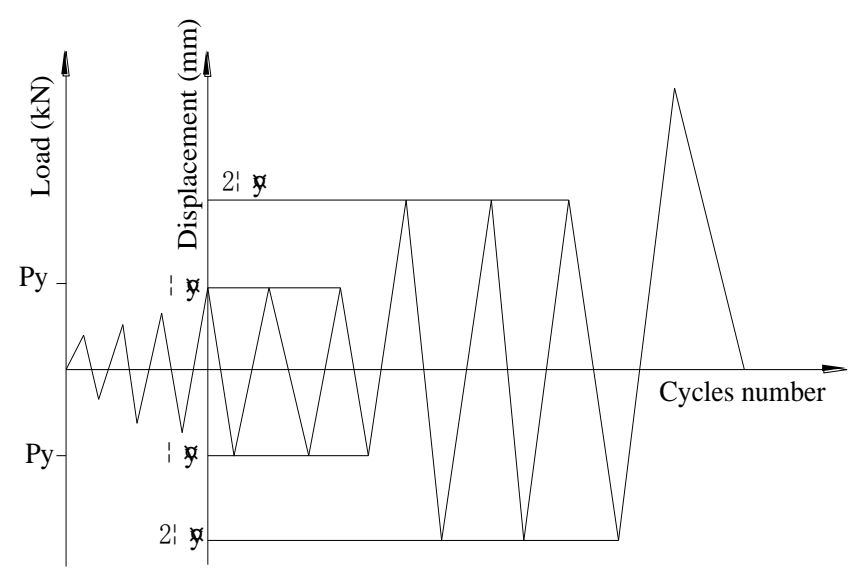

Fig. (4). Load program.

\section{TEST OBSERVATIONS}

During the initiation of loading, specimen BW9 was in elastic stage, the lateral load-displacement of loading process was coincide with unloading process. When the lateral load was $462 \mathrm{kN}$, horizontal cracks were appeared at the bottom of the tension side. As the load increasing, the horizontal bending crack become the flexure-shear crack, and extended along the diagonal direction. When the lateral load was $853 \mathrm{kN}$, the tensile reinforcement yielded. When the displacement was $60 \mathrm{~mm}$, the reinforcement at the bottom of the wall was exposed and the concrete was crushed, which the specimen failed.

During the initiation of loading, specimen GJ9 was in elastic stage, the lateral load-displacement of loading process was coincide with unloading process. When the lateral load was $550 \mathrm{kN}$, horizontal cracks were appeared at the bottom of the tension side. As the load increasing, the horizontal bending crack become the flexure-shear crack, and extended along the diagonal direction. When the lateral load was $830 \mathrm{kN}$, the tensile reinforcement yielded. When the displacement was $70 \mathrm{~mm}$, the reinforcement at the bottom of the wall was exposed and the concrete was crushed, which the specimen failed.

During the initiation of loading, specimen BW7 was in elastic stage, the lateral load-displacement of loading process was coincide with unloading process. When the lateral load was $300 \mathrm{kN}$, horizontal cracks were appeared at the bottom of the tension side. As the load increasing, the horizontal bending crack become the flexure-shear crack, and extended along the diagonal direction. When the lateral load was $778 \mathrm{kN}$, the tensile reinforcement yielded. When the displacement was $55 \mathrm{~mm}$, the reinforcement at the bottom of the wall was exposed and the concrete was crushed, which the specimen failed.

\section{TEST RESULT AND DISCUSSION}

\subsection{Hysteretic Response}

The measured load-displacement hysteretic hoops are shown in Fig. (5). For all of the three specimens, the loaddisplacement hysteretic hoops have the similarity: Before the specimen yielded, the area of hysteretic hoops increased with the increasing of the load, and the area was small because of the small residual deformation. After the specimen yielded, the area of hysteretic hoops increased. When the displacement was same, the loading stiffness and strength of next cycle degraded obviously compared with last cycle, but the degradation of unloading stiffness was not obvious. The hysteretic hoops looks like reverse $\mathrm{S}$ shape, which means the specimen had good energy-absorbing capacity. After the specimen reached the ultimate load, the load capacity declined slowly, which means the specimen had good ductility. Hysteretic performance of BW9 and GJ9 was close, and hysteretic performance of BW7 was poor.

\subsection{Displacement Ductility}

The measured load-displacement skeleton curves are shown in Fig. (6). It can be seen that the shapes of the three specimens are similarity, the bearing capacity of BW9 and GJ9 is close, which is larger than BW7. 


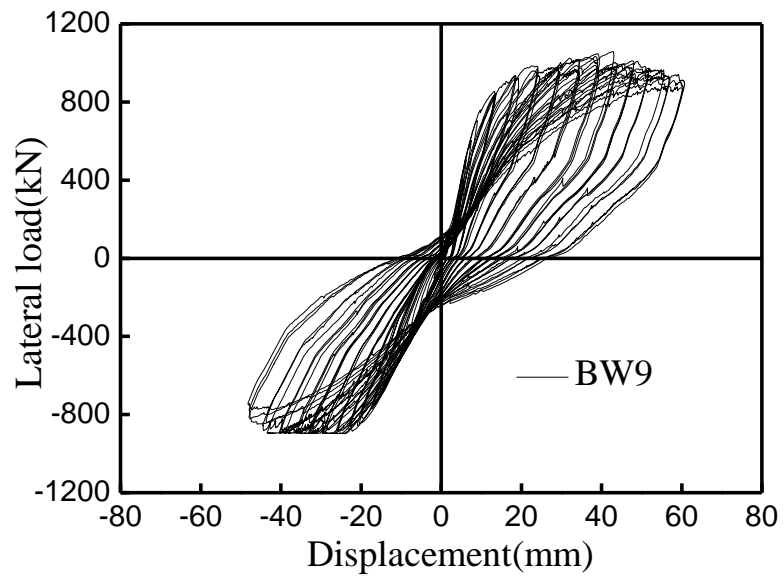

(a) BW9

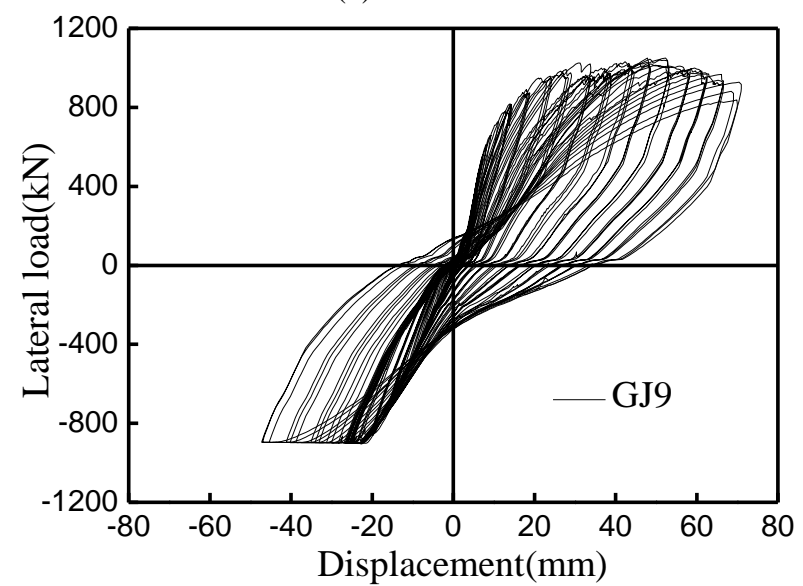

(b) GJ9

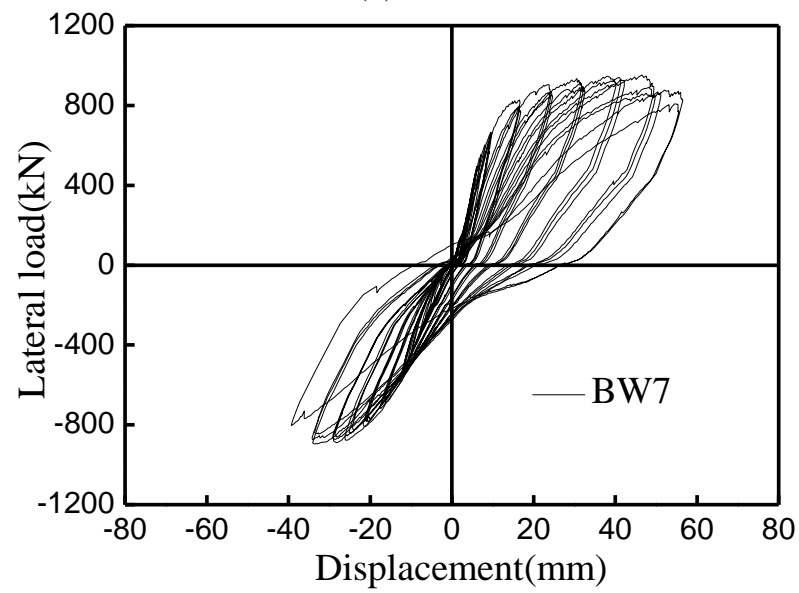

(c) BW7

Fig. (5). Load-displacement hysteretic loops of specimens.

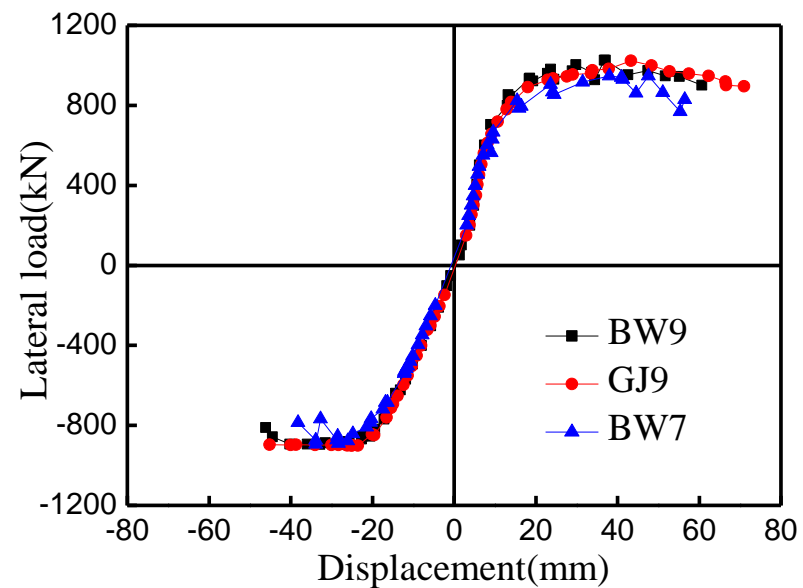

Fig. (6). Load-displacement skeleton curves.

Table $\mathbf{3}$ compares performance measures of the specimens in bearing capacity and ductility. The data represent the averages of the push and pull direction. Fig. (7) describes the definition of yield displacement and displacement ductility. Where $\Delta \mathrm{y}$ is the yield displacement that is determined according to energy method, $\Delta u$ is the displacement when the lateral load attains ultimate bearing capacity.

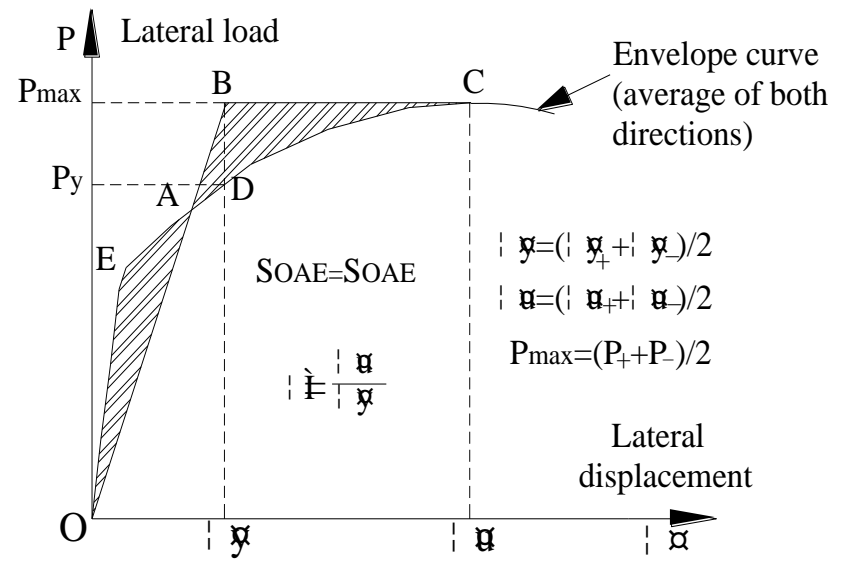

Fig. (7). Displacement ductility parameters.

It can be seen from the table that the yield displacements of the specimens are close, which means that the behaviour of hole formed by drawing out the screwed steel pipes and prefabricated corrugated pipe basically the same before yielding. The ultimate displacement and ductility of BW9 is smaller than GJ9, which means the deformation capacity of hole formed by drawing out the screwed steel pipes better

Table 3. Test results.

\begin{tabular}{|c|c|c|c|c|c|c|c|}
\hline NO & $\mathbf{N}_{\mathbf{c r}}(\mathbf{k N})$ & $\boldsymbol{\Delta}_{\mathbf{c r}}(\mathbf{m m})$ & $\mathbf{N}_{\mathbf{y}}(\mathbf{k N})$ & $\boldsymbol{\Delta}_{\mathbf{y}}(\mathbf{m m})$ & $\mathbf{N}_{\mathbf{u}}(\mathbf{k N})$ & $\boldsymbol{\Delta}_{\mathbf{u}}(\mathbf{m m})$ & $\boldsymbol{\mu}$ \\
\hline \hline BW9 & 462 & 5.9 & 853 & 13.2 & 1034 & 60.4 & 4.7 \\
\hline GJ9 & 550 & 7.2 & 830 & 15.4 & 1023 & 71.4 \\
\hline BW7 & 300 & 4.3 & 778 & 13.7 & 910 & 55.3 & 4.0 \\
\hline
\end{tabular}

Note: where $\mathrm{N}_{\mathrm{cr}}$ is crack load, $\Delta_{\mathrm{cr}}$ is crack displacement $\mathrm{N}_{\mathrm{y}}$ is yield load, $\Delta_{\mathrm{y}}$ is yield displacement, $\mathrm{N}_{\mathrm{u}}$ is ultimate load, $\Delta_{\mathrm{u}}$ is ultimate displacement, $\mu$ is displacement ductility. 
Table 4. Equivalent viscous damping coefficient.

\begin{tabular}{|c|c|c|c|}
\hline Specimen & BW9 & GJ9 & BW7 \\
\hline \hline Crack stage & 0.3918 & 0.3788 & 0.3933 \\
\hline Yielding stage & 0.3533 & 0.3997 & 0.4045 \\
\hline Ultimate stage & 0.4145 & 0.3979 & 0.3779 \\
\hline
\end{tabular}

than prefabricated corrugated pipe. The ultimate displacement and ductility of BW9 is smaller than BW7, which means that the reducing of splicing length declines the deformation capacity.

\subsection{Stiffness Degradation}

The stiffness degradation curves are shown in Fig. (8). Stiffness degradation is an important behavior for seismic performance of structure. The cumulative damage in the structure would cause stiffness degradation, which can be expressed with equivalent stiffness $\mathrm{K}=\mathrm{F} / \Delta$, where $\mathrm{K}$ is the equivalent stiffness, $\mathrm{F}$ is the load, $\Delta$ is the displacement.

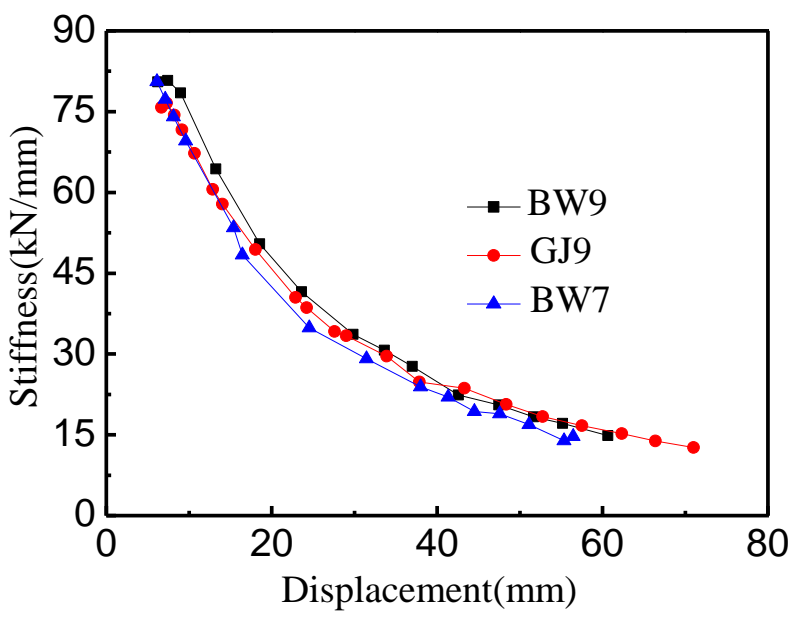

Fig. (8). Stiffness degradation.

It can be seen from Fig. (8) that the stiffness decreases with the increasing of displacement. At initial stage, the stiffness decreases quickly, and then the tendency slows down with the increasing of displacement. As the displacement is same, the stiffness of BW7 is the smaller than others. As the displacement is small, the stiffness of BW9 is smaller than GJ9, and the stiffness of BW9 begins to be larger than GJ9 with the increasing of displacement.

The above analysis shows that the stiffness of hole formed by drawing out the screwed steel pipes and prefabricated corrugated pipe is basically the same. The reducing of splicing length would bring down the stiffness of specimen.

\subsection{Energy Dissipation Capacity}

The equivalent viscous damping coefficient $\left(h_{\mathrm{e}}\right)$ is commonly used to determine the energy dissipation capacity of the structures and members in the earthquake. The equivalent viscous damping coefficient of different stage is listed in Table 4. It can be seen that the equivalent viscous damping coefficients of specimens are close, which means that the energy dissipation capacity basically the same.

\section{CONCLUSION}

Three full-scale pre-cast concrete walls were tested under low cycle loading. The following conclusions can be drawn from the work reported above.

1. As the axial compression ratio and splicing length is same, the hysteretic curve, ductility, stiffness degradation and energy dissipation capacity are similarity, which means that the two kinds of splicing method have equal seismic performance.

2. As the splicing length reducing, the behavior of the specimen is influenced, and the splicing length meets the requirements of seismic code.

3. The hysteretic curves of the specimens are full, the energy dissipation capacities good. The displacement ductility coefficients are greater than 4 , which meet the requirements of ductility.

\section{CONFLICT OF INTEREST}

The authors confirm that this article content has no conflict of interest.

\section{ACKNOWLEDGEMENTS}

This work was performed under the support of Twelfth Five-Year National Science and Technology Support (2012BAJ16B05) and The items of high-level personnel North China university of water conservancy and hydropower (201341).

\section{REFERENCES}

[1] Z.F. Zhu and Z.X. Guo, "Seismic test and analysis of joints of new pre-cast concrete shear wall structures", China Civil Engineering Journal, vol. 45, no. 1, pp. 69-76, 2012.

[2] Z.X Guo, N.C Dong, and Z.F. Zhu, "Development of construction technology of pre-cast concrete structure in buildings", Construction Technology, vol. 40, no. 11, pp. 1-3, 2011.

[3] J.R. Qian , X.K. Yang, and H. Qing, "Tests on seismic behavior of pre-cast shear walls with various methods of vertical reinforcement splicing", Journal of Building Structures, vol. 32, no. 6, pp. 51-59, 2011.

[4] J.R. Qian, Y.Y. Peng, and H. Qing, "Tests on seismic behavior of pre-cast shear walls with vertical reinforcements spliced by grout sleeves", Building Structure, vol. 41, no. 2, pp. 7-11, 2011.

[5] H.B. Jiang, H.S. Zhang, and W.Q. Liu, "Experimental study on plug-in filling hole for steel bar anchorage of the PC structure", Journal of Harbin Institute of Technology, vol. 43, no. 4, pp. 28 -31, 2011.

[6] O.A. Pekau, Z.A. Zielinski, and A.W.K. Lee and D. Hum, "Dynamic effects of panel failure in precast concrete shear walls", ACI Structural Journal, vol. 85, no. 3, pp. 277-285,1988. 
[7] S. Mochizuki, "Experiment on slip strength of horizontal joint of precast concrete multi story shear walls", Eleven World Conference on Earthquake Engineering, vol. 194, pp. 1-8, 1996,

[8] G Harry, and G Harris, "Static and dynamic testing of model precast concrete shear walls of large panel buildings", Special Publication, vol. 3, pp. 205-237, 1982.

[9] M.G. Oliva, R.W. Clough, M.V. Gavrilovic, and Predrag, Correlation of Analytical and Experimental Responses of Large-Panel Pre-Cast Building Systems, Earthquake Engineering Research Centre, University of California, Berkeley, p. 106, 1988.
[10] S. Nazzal, "Effect of axial load on hysteretic behavior of precast bearing shear walls", In: The International Earthquake Engineering Conference, Dead sea, pp. 1-9, 2005.

[11] W.Q. Liu, H.B. Jiang, and Y.C. Gen, "A plug-in filling hole for steel bar anchorage", China Patent, ZL2008 20090150, 2009.

[12] O.A Pekau, "Influence of vertical joints on the earthquake response of precast panel walls", Building and Environment, vol. 16, no. 2, pp. 153-162, 1981.

Received: September 17, 2014

Revised: December 17, 2014

Accepted: December 23, 2014

(c) Yajun and Naiyan; Licensee Bentham Open.

This is an open access article licensed under the terms of the Creative Commons Attribution Non-Commercial License (http://creativecommons.org/licenses/ by-nc/3.0/) which permits unrestricted, non-commercial use, distribution and reproduction in any medium, provided the work is properly cited. 